\title{
Silica deposition and phenotypic changes to Thermus thermophilus cultivated in the presence of supersaturated silicia
}

\author{
Satoru Iwai ${ }^{1}$, Katsumi Doi ${ }^{2}$, Yasuhiro Fujino ${ }^{2}$, Takeo Nakazono ${ }^{1}$, Kosai Fukuda ${ }^{1}$, \\ Yoshinobu Motomura ${ }^{3}$ and Seiya Ogata ${ }^{1}$ \\ ${ }^{1}$ Department of Applied Microbial Technology, Faculty of Biotechnology and Life Science, Sojo University, \\ Kumamoto, Japan; ${ }^{2}$ Department of Genetic Resources Technology, Faculty of Agriculture, Kyushu University, \\ Higashi-ku, Fukuoka, Japan and ${ }^{3}$ Department of Earth and Planetary Science, Faculty of Science, Kyushu \\ University, Higashi-ku, Fukuoka, Japan
}

\begin{abstract}
Thermus thermophilus cells formed siliceous deposits in the presence of supersaturated silicic acid (600 p.p.m $\mathrm{SiO}_{2}$ ). The supersaturated silicic acid promoted interaction between cells and the inside walls of glass culture bottles, leading to the development of cell aggregates or biofilms. Electron probe microanalysis showed that within the aggregates most of the cell surfaces were covered with silica. Under these conditions, there was remarkable production of silica-induced protein (Sip), a solute-binding component of the $\mathrm{Fe}^{3+}$-binding $\mathrm{ABC}$ transporter. Furthermore, supersaturated silica enhanced resistance to the peptide antibiotics bacitracin, colistin and polymyxin B, which all act on the cell envelope. By contrast, supersaturated silica did not induce resistance to ampicillin, chloramphenicol, kanamycin and tetracycline, which inhibit peptide synthesis. Although strong expression of Sip was detected in liquid cultures of $T$. thermophilus in the presence of supersaturated silica and colistin, upregulated transcription of putative efflux pump and multidrug resistance $A B C$ transporter genes were not detected by quantitative real-time PCR analysis. These findings suggest Sip promotes silica deposition on the surfaces of cells, after which the silicified outer membrane may serve as a 'suit-of-armor,' conferring resistance to peptide antibiotics.

The ISME Journal (2010) 4, 809-816; doi:10.1038/ismej.2010.12; published online 11 March 2010

Subject Category: geomicrobiology and microbial contributions to geochemical cycles

Keywords: Thermus thermophilus; silicic acid; antibiotic resistance; cell adhesion
\end{abstract}

\section{Introduction}

Silica deposition is an ongoing and often problematical process in many modern hot spring systems. For example, the siliceous deposits (called silica scale) formed on the surface of the equipment and in the pipelines at geothermal power plants have a significant negative economic impact related to energy loss and maintenance costs (Inagaki et al., 2003). Microscopic observation of these silicious deposits reveals numerous microbe-like structures, and it has been suggested that these fossils represent archaic microorganisms that grew in the hot, supersaturated fluids (Cook and Stakes, 1995; Yee et al., 2003; Handley et al., 2008). There have been a number of studies characterizing the physical changes associated with various bacteria during silicification (Toporski et al., 2002; Phoenix et al.,

Correspondence: S Ogata, Department of Applied Microbial Technology, Faculty of Biotechnology and Life Science, Sojo University, 4-22-1 Ikeda, Kumamoto 860-0082, Japan.

E-mail: ogata28@bio.sojo-u.ac.jp

Received 30 November 2009; revised 14 January 2010; accepted 17 January 2010; published online 11 March 2010
2003; Lalonde et al., 2005; Orange et al., 2009); however, the molecular mechanisms underlying microbial silicification remain poorly understood.

We previously observed numerous bacteria within the silica scale at a geothermal power plant, and after examining their population and its characteristics, we suggested that it is the extremely thermophilic bacteria that participate in forming the siliceous deposits (Inagaki et al., 1997, 1998, 2001). One of these bacteria, Thermus thermophilus TMY, was isolated from the silica scale (Fujino et al., 2008) and was found to induce precipitation of supersaturated amorphous silica ( $>400$ p.p.m $\mathrm{SiO}_{2}$ ) during its log-growth phase (Inagaki et al., 1998). Moreover, a protein of $\sim 35 \mathrm{kDa}$, called silicainduced protein (Sip), was induced in the presence of supersaturated silica and was isolated from the cell envelope fraction of the TMY cells (Doi et al., 2009). The amino-acid sequence of Sip is similar to that of the predicted solute-binding component of the $\mathrm{Fe}^{3+}$-binding $\mathrm{ABC}$ transporter in T. thermophilus HB8. What's more, sip gene is situated as a component of the Fbp-type ABC transporter operon, and a Sip-like protein was also induced in strain 
HB8 in the presence of supersaturated silicic acid. Only very small amounts of Sip are detected in cells cultivated without silica, but marked Sip production is initiated within $1 \mathrm{~h}$ after addition of supersaturated silicic acid (Doi et al., 2009). Notably, silica-induced changes in protein expression were also recently observed in Anabaena sp. (Konhauser et al., 2008), suggesting that silica stress may induce protein expression in a variety of thermophiles.

There have been many reports focusing on the function and/or gene expression of $\mathrm{Fe}^{3+}$-binding ABC transporters and on similar membrane transporters and secretion systems in gram-negative pathogenic bacteria such as Pseudomonas and Salmonella (Fath and Kolter, 1993; Higgins, 1995). It is known that some of these transporters have key functions in mediating surface adherence (Costerton et al., 1999; Drenkard, 2003; Gooderham et al., 2008) and/or antibiotic resistance (Gunn et al., 1998; Zhou et al., 2001; Lee et al., 2004; Nishino et al., 2006). For thermophilic microorganisms, surface adherence seems to actively contribute to the rapid formation of large siliceous deposits, suggesting that the deposits are important for the maintenance of their position and survival within the limited niches of geothermal environments. Indeed, Phoenix and Konhauser (2008) suggested that bacterial biomineralization acts as a protective screen against UV and dehydration and provide a source of essential nutrients for growth and protection against toxins-that is biomineralization acts as a 'suit-ofarmor,' protecting the organism and creating a more favorable growth environment.

With that as background, our work has focused on characterizing the physiological changes that Thermus species undergo during in vitro biosilicification. In this study, we examined the development of cell adherence and drug resistance along with silica deposition during the growth of $T$. thermophilus in the presence of supersaturated silicic acid.

\section{Materials and methods}

\section{Bacterial strains and cultural conditions}

T. thermophilus TMY (JCM 10668) and T. thermophilus HB8 (ATCC 33923) were used in this work. The former was isolated from silica scale formed in geothermal water at a geothermal power plant in Japan (Fujino et al., 2008). The optimum temperature for cultivation was $75^{\circ} \mathrm{C}$ for strain TMY and $70{ }^{\circ} \mathrm{C}$ for strain HB8. These strains were routinely grown under strong aeration (200 r.p.m) in TM liquid medium (Fujino et al., 2008). Prior to use, the $\mathrm{pH}$ of the medium was adjusted to 7.2 with $\mathrm{HCl}$, after which it was autoclaved. A stock solution of silicic acid was prepared by dissolving sodium metasilicate in $10 \mathrm{mM} \mathrm{NaOH}$, as described earlier. In this work, the concentration of silicic acid in the TM medium was 600 p.p.m, which is the average concentration in geothermal water at geothermal power plants (Inagaki et al., 1998).

\section{Turbidity measurement}

The optical density (OD) of cultures was measured at $660 \mathrm{~nm}$ using a photoelectric colorimeter (TAITEC MiniPhoto 518R; Taitec Co. Ltd, Tokyo, Japan).

\section{Scanning electron microscopy and electron probe microanalysis}

Cell aggregates on the glass surface of culture bottles were examined using a JEOL JCXA-733 electron microprobe analyzer (JEOL Ltd., Tokyo, Japan) to identify silicon and other metallic minerals (relative qualitative analysis) (Inagaki et al., 2001).

\section{Antibiotic sensitivity}

The antibiotics used in this study were ampicillin (Nacalai Tesque, Kyoto, Japan), bacitracin (SigmaAldrich Co., St Louis, MO, USA), chloramphenicol (Wako Pure Chemical Industries Ltd., Osaka, Japan), colistin (Wako), kanamycin (Sigma-Aldrich), polymixin B (Wako), streptomycin (Meiji Seika Kaisha Ltd., Tokyo, Japan), tetracycline (Sigma-Aldrich) and thiostrepton (Sigma-Aldrich). Antibiotic sensitivity was preliminarily tested using the dilution method on solid medium containing $2.0 \%$ Gellan Gum (Wako), with or without silicic acid. The minimum inhibitory concentration of each antibiotic was determined and expressed as $\mu$ g per ml. Cells were also exposed to antibiotics in TM broth with or without 600 p.p.m silicic acid, and the $\mathrm{OD}_{660}$ of the cultures was monitored for $12 \mathrm{~h}$.

\section{RNA preparation}

After exposure to $5 \mu \mathrm{g} \mathrm{ml}^{-1}$ colistin for $1 \mathrm{~h}$, with or without 600 p.p.m silica, T. thermophilus HB8 cells were placed in two volumes of RNAprotect Bacteria Reagent (QIAGEN GmbH, Hilden, Germany) for $10 \mathrm{~min}$. The cells were then collected, and the crude RNA was extracted by the addition of $1.4 \mathrm{ml}$ of solution containing $5 \mathrm{mM}$ Tris-HCl (pH 7.5), $5 \mathrm{mM}$ EDTA, $0.25 \%$ SDS and 50\% water-saturated phenol. This mixture was incubated at $65^{\circ} \mathrm{C}$ for $5 \mathrm{~min}$, chilled on ice for $5 \mathrm{~min}$, and then centrifuged at $4{ }^{\circ} \mathrm{C}$. Thereafter, $750 \mu \mathrm{l}$ of TRIZOL LS (Life Technologies Corporation, Carlsbad, CA, USA) was added to $0.2 \mathrm{ml}$ of the aqueous phase and after incubation for $5 \mathrm{~min}$ at room temperature, the RNA was extracted using $0.2 \mathrm{ml}$ of chloroform. The extraction was then repeated with $0.5 \mathrm{ml}$ of chloroform, after which the crude RNA was purified using an RNeasy mini kit (QIAGEN) according to the manufacturer's instructions, which included digestion with DNase I to remove any contaminating DNA. RNA concentrations were calculated using NanoDrop 1000 (Thermo Fisher Scientific Inc., Waltham, MA, USA). 
Primer design and quantitative real-time PCR

The primers designed for quantitative real-time PCR were 19-21 bases long, had a G/C content >50\% and a Tm of about $60^{\circ} \mathrm{C}$. The length of the PCR products ranged from 90 to $160 \mathrm{bp}$ (Table 1). Primer3 design software (http://primer3.sourceforge.net/) was used to select the primer sequences. Quantitative real-time PCR were performed using a One Step SYBR PrimeScript RT-PCR Kit II (TAKARA BIO Inc., Otsu, Japan) in a LightCycler 2.0 (Roche Diagnostics $\mathrm{GmbH}$, Basel, Switzerland) according to the manufacturer's instructions. The reverse transcription step was carried out at $42^{\circ} \mathrm{C}(5 \mathrm{~min})$ and was followed by denaturation of the reverse transcriptase by heating at $95{ }^{\circ} \mathrm{C}$ for $10 \mathrm{~s}$. The amplification protocol entailed 40 cycles of $95^{\circ} \mathrm{C}$ for $5 \mathrm{~s}$ and $60{ }^{\circ} \mathrm{C}$ for $20 \mathrm{~s}$. After the amplification, melting curve analysis was carried out at temperatures ranging from 65 to $95{ }^{\circ} \mathrm{C}$. A standard curve was generated for the relative quantification of all genes, and a control reaction lacking reverse transcriptase was performed for every RNA sample. The copy number of each sample was calculated from the means of triplicate PCR sample. The gyrase subunit B $(g y r B)$ gene was used as a housekeeping gene to normalize the amount of RNA in each reaction.

\section{Results and discussion}

Surface adherence of cells during growth in the presence of supersaturated silicic acid

T. thermophilus strains TMY and HB8 form yellow or yellowish orange colonies, reflecting the presence of carotenoid pigments. During growth in the presence of supersaturated silicic acid, the cells adhered to the glass surface of the culture bottles (Figure 1). Thanks to the yellow or orange coloration, adhesion of the cells was easily observable where the edge of the liquid cultures (Figures $1 \mathrm{~b}$ and c). The cell adhesion was first visually detectable after $7-8 \mathrm{~h}$ of culture, and with further cultivation developed into adherent cell aggregates resembling biofilm. This aggregation of adherent cells reached a maximum after about $36 \mathrm{~h}$ and persisted for an additional $12 \mathrm{~h}$ with the limited nutrition available in a bottle culture. We previously observed that in cultures containing 600 p.p.m silicic acid, in vitro silica deposition with considerable Sip production was detectable after 6-7 h (mid-log phase) (Doi et al., 2009). The levels of Sip production peaked after 8-10 h, and the level of silica deposition peaked after 30-36 h. The progression of the cell adhesion could be closely related to Sip production and silica deposition, as there was little cell adhesion in the presence of a lower concentration of silicic acid (<400 p.p.m) (Figure 1a). There was no deposition of silica in cell-free cultures containing 600 p.p.m silicic acid, even after $120 \mathrm{~h}$ (data not shown).

To obtain information about the bacterial cell aggregates that formed on the glass surface of the culture bottles and the $\mathrm{Si}$ distribution, we next examined the cells using electron probe microanalysis (Figure 2). Scanning electron microscopy examination of TMY cell aggregates formed in silica-free medium showed clumps of individual rod-shaped cells (Figure 2a), whereas Si mapping revealed that very little Si was present (Figure $2 b$ ). By contrast, when cell aggregates formed in the presence of supersaturated silicic acid, cells embedded in silica particles were observed within the aggregates (Figure 2c), and strong $\mathrm{Si}$ signals were detected (Figure 2d). On the other hand, there were no differences between $\mathrm{Si}$-free and supersaturated $\mathrm{Si}$ cultures with respect to other elements, including $\mathrm{Na}, \mathrm{K}, \mathrm{Ca}, \mathrm{Mg}$ and $\mathrm{Fe}$. The same results were obtained with HB8 cell aggregates. We therefore suggest that the $T$. thermphilus cells strongly interact with silica, and that the observed deposition of silica on the glass surface of culture bottles was not caused by evaporation. In addition, these results suggest that silica is an important component supporting the formation of cell aggregates and biofilms on the surface of inorganic materials.

Responses of strains TMY and HB8 to antibiotics in supersaturated silicic acid

When we examined the ability of antibiotics to inhibit the growth of T. thermophilus strain TMY on TM agar plates, we found that the minimum inhibitory concentrations were $0.1,0.5,1,5,5,5$, 1, 1 and $0.5 \mu \mathrm{g} \mathrm{ml}^{-1}$ for ampicillin, bacitracin, chloramphenicol, colistin, kanamycin, polymixin B, streptomycin, tetracycline and thiostrepton, respectively. Nearly the same effects were obtained

Table 1 Primers used in this study

\begin{tabular}{llll}
\hline Gene name & Forward primer $\left(5^{\prime}-3^{\prime}\right)$ & Reverse primer $\left(5^{\prime}-3^{\prime}\right)$ & Annotation for product \\
\hline TTHA0263 & CTCGCCCTCAACCTTTCCA & CACGACCCCGTAGAAGACCA & Multidrug efflux transporter \\
TTHA0351 & CACCAACGACCTCTTCTCCA & GGAGTAGGCGGAAACCAGAA & Efflux protein (fosmidomycin resistance) \\
TTHA0554 & TCCCGAGGTCTACGTCCTTCT & ACGAGGAGGTTCCCCAAGAG & Small multidrug export protein \\
TTHA0729 & GCGTTTTGGGCTTCACCTAC & GCGGTAGCGGTCAATGTTTT & AcrB/AcrD/AcrF family efflux transporter \\
TTHA1004 & GCCTTTCCGAAAACCTCTCC & GTTCCCCTCTGCCTTGAGTT & Outer membrane efflux protein \\
TTHA1315 & AGTTTCTGCCCTCCCTCCTC & CAGCCCGTGTAGACCAAGAA & Putative integral membrane efflux protein \\
TTHA1341 & GGAAGAAGAGGGCGAACCA & AAAGGGAGCGGGAGGAGAAG & ABC-type multidrug transport system \\
sip & ACCCGCTTCCTCACCTACCT & GTCCAGCTTGGGGCTTTTC & Silica-induced protein (iron ABC transporter)
\end{tabular}




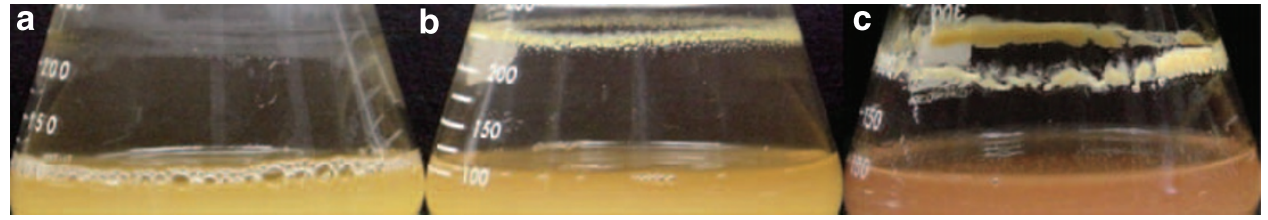

Figure 1 Photographs showing the adhesion of cells and cell aggregates to the glass surface of culture bottles in the presence and absence of supersaturated silicic acid. (a and b) T. thermophilus TMY culture grown for $36 \mathrm{~h}$ at $75^{\circ} \mathrm{C}$ in the absence (a) and presence (b) of supersaturated silicic acid (600 p.p.m). (c) T. thermophilus HB8 culture grown for $36 \mathrm{~h}$ at $70^{\circ} \mathrm{C}$ in supersaturated silicic acid (600 p.p.m).
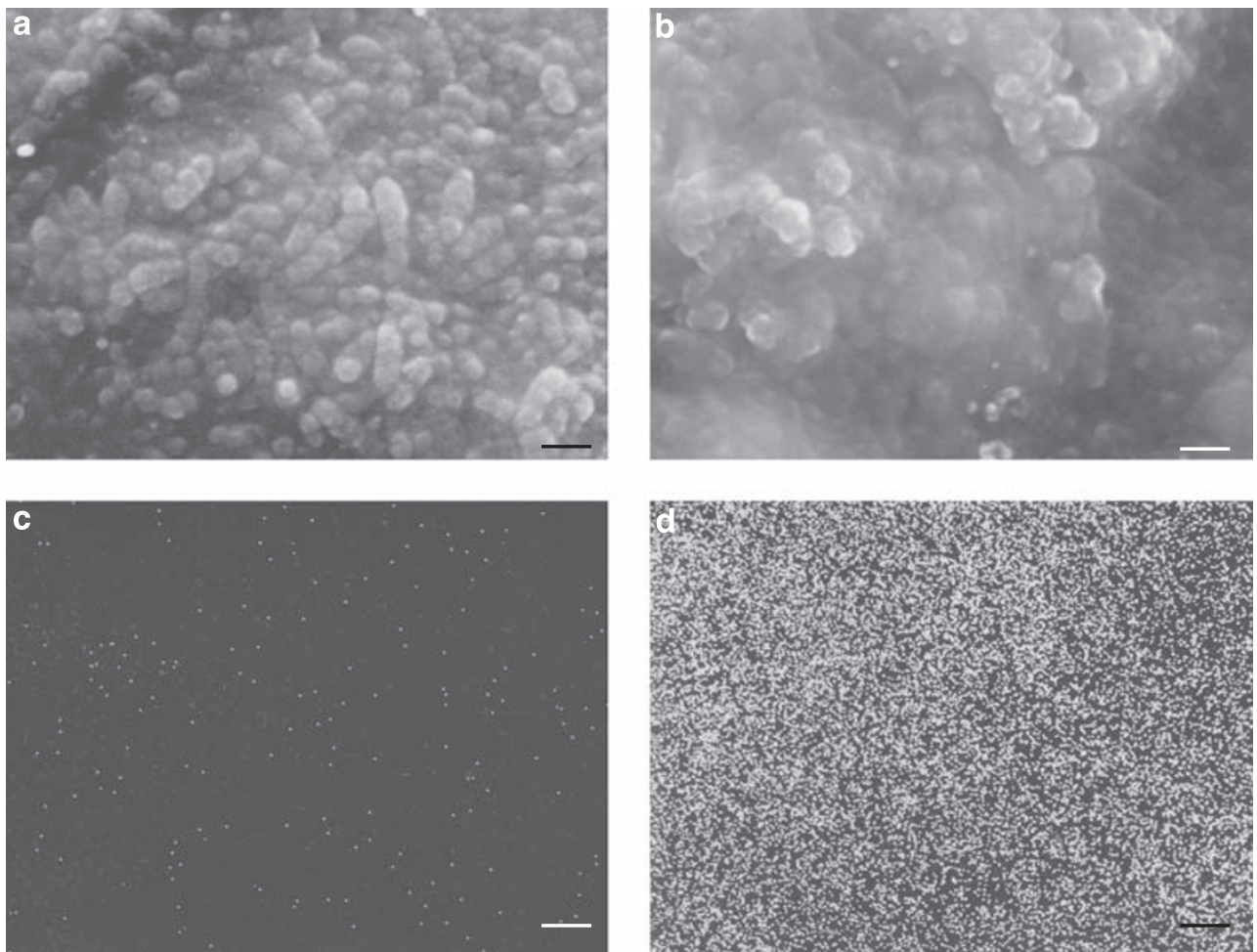

Figure 2 Scanning electron micrographs and silicon distribution images of cell aggregates obtained using electron probe microanalysis. (a and b) Scanning electron microscopy images of T. thermophilus TMY cell aggregates in the absence (a) and presence (b) of supersaturated silicic acid. (c and d) Silicon mapping of cell aggregates grown in the absence (c) and presence (d) of supersaturated silicic acid. Bars indicate $1 \mu \mathrm{m}$.

with strain HB8. For some of the antibiotics, however, we noticed a difference in sensitivity in the presence and absence of supersaturated silicic acid. Both strains appeared to be rendered resistant to bacitracin, colistin and polymyxin $\mathrm{B}$ in the presence of supersaturated silicic acid in the solid medium (data not shown).

To confirm this observation, we also tested the sensitivity to antibiotics of strains TMY and HB8 in liquid cultures. The growth tendencies and $\mathrm{OD}_{660}$ of the liquid cultures of both strains were nearly the same in the absence and presence of supersaturated silicic acid (600 p.p.m). On the other hand, with the addition by supersaturated silicic acid, the bacteria exhibited three patterns of sensitivity to the antibiotics tested (Figures 3 and 4). Their sensitivity to ampicillin, chloramphenicol, kanamycin, streptomycin and thiostrepton was nearly the same in the presence and absence of supersaturated silica-that is the growth tendencies and the $\mathrm{OD}_{660}$ of the cultures were about the same (Figure 3). The susceptibility to tetracycline increased somewhat in the presence of supersaturated silica (Figure 3), though the pattern remained consistent with the aforementioned antibiotics in that supersaturated silicic acid did not confer resistance to the antibiotic. With the peptide antibiotics bacitracin, colistin and polymyxin B, however, we observed greater growth of both strains in the presence of supersaturated silicic acid than in its absence (Figure 4). This means that both strains are highly susceptible to these peptide antibiotics in the absence of supersaturated silicic acid, but their sensitivity is diminished by the presence of supersaturated silicic acid. Moreover, when antibiotics were added after $4-7 \mathrm{~h}$ of culture with 600 p.p.m 
silicic acid, the antibiotic resistance was more pronounced than after $0-2 \mathrm{~h}$; little growth inhibition was seen, with or without silicic acid, when antibiotics were added after $8 \mathrm{~h}$ (data not shown).

Bacitracin acts by interfering with the dephosphorylation of $\mathrm{C}_{55}$-isoprenyl pyrophosphate, a

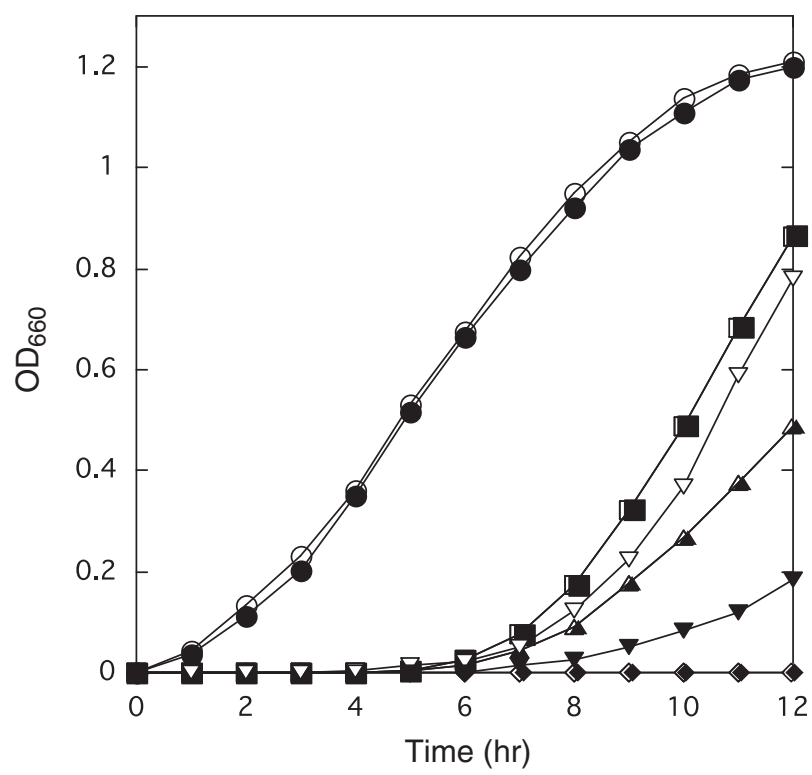

Figure 3 Effect of six representative antibiotics on the growth of T. thermophilus TMY in the presence and absence of supersaturated silica. Open symbols show the growth curve in the absence of supersaturated silicic acid. Filled symbols show the growth curve in the presence of supersaturated silicic acid (600 p.p.m). $\bigcirc \bullet$, no antibiotics; $\square \mathbf{\square}$, chloramphenicol $\left(1 \mu \mathrm{g} \mathrm{ml}^{-1}\right) ; \Delta \boldsymbol{\Delta}$, kanamycin $\left(5 \mu \mathrm{g} \mathrm{ml}^{-1}\right) ; \diamond \diamond$, ampicillin $\left(0.1 \mu \mathrm{g} \mathrm{ml}^{-1}\right) ; \nabla \boldsymbol{\nabla}$, tetracycline $\left(0.5 \mu \mathrm{g} \mathrm{ml}^{-1}\right)$. The data represent the average of five or more independent experiments. Standard deviations for each experiment were not greater than $\pm 5 \%$ of the value shown. Strain HB8 shows nearly the same growth patterns as strain TMY. molecule that carries the building blocks of the peptidoglycan cell wall outside the inner membrane (Stone and Strominger, 1971). Colistin is a cyclic cationic peptide that kills gram-negative bacteria by interacting with and disrupting the outer membrane (Sun et al., 2009). Polymyxin B is a polycationic peptide that disrupts the bacterial cell membrane by interacting with its phospholipids (Roes et al., 2005). That these antibiotics all attack the cell envelope suggests supersaturated silicic acid induces phenotypic changes in the Thermus cell envelope that lead to an increase in peptide antibiotic resistance. As the other antibiotics tested in this study inhibit protein or peptide synthesis, phenotypic changes to the cell envelope induced by supersaturated silicic acid had little or no effect on the bacteria's resistance to these drugs.

Bacterial growth in the presence of iron ion or other metal ions reportedly results in modification of surface substances (for example lipopolysaccharide) that renders the organisms resistant to antibiotics such as polymixin B. In Pseudomonas and Salmonella, for example, iron ion or $\mathrm{Mg}^{2+}$ affects the PmrA/PmrB system, which consists of an efflux pump (PmrA) and a sensor protein (PmrB) that regulates some surface modifications, including modification of lipopolysaccharide, rendering the organisms resistant to polymixin B (Groisman et al., 1997; Mcphee et al., 2003; Lee et al., 2004; Gooderham et al., 2008). In this study, however, supersaturated silicic acid induced expression of the ABC transporter component Sip, which rendered the cells resistant to peptide antibiotics like those produced by the soil bacterium Bacillus subtilis and related species. In that regard, Wösten et al. (2000) proposed that resistance to polymyxin B would be important for the natural habitation of bacteria. Moreover, the observed increase in
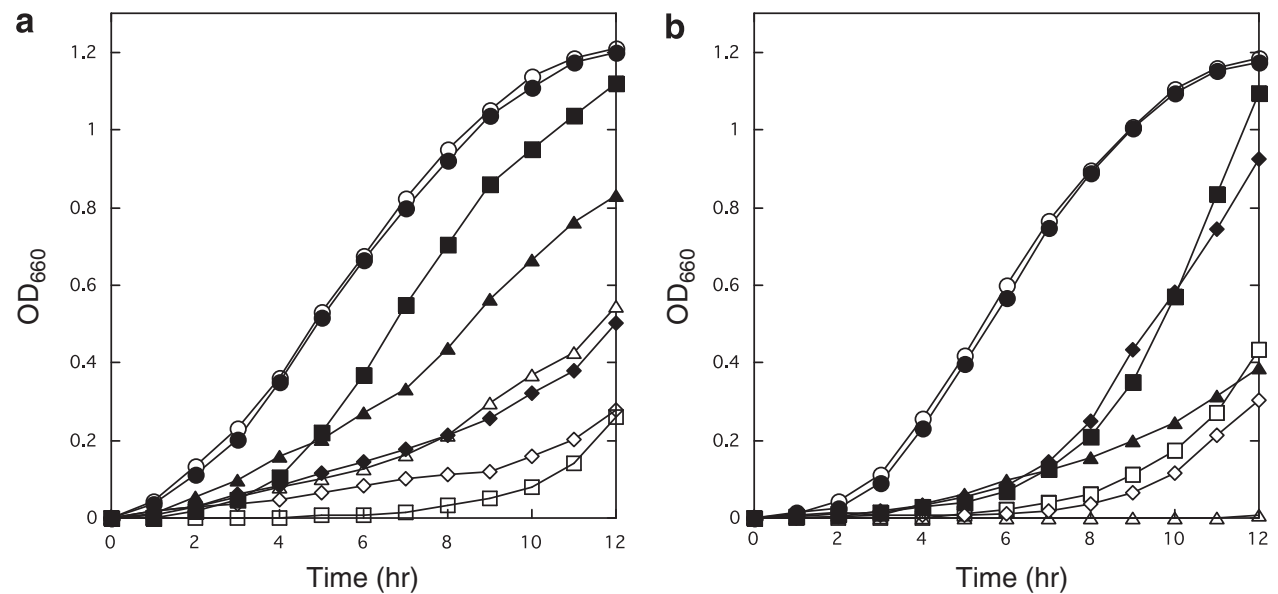

Figure 4 Effect of three peptide antibiotics on the growth of T. thermophilus strains TMY and HB8 in the presence and absence of supersaturated silica. (a) Strain TMY; (b) strain HB8. Open symbols show growth curves in the absence of supersaturated silicic acid. Closed symbols show growth curves in the presence of supersaturated silicic acid (600 p.p.m). $\bigcirc \bullet$, no antibiotics; $\diamond \bullet$, bacitracin $\left(0.5 \mu \mathrm{g} \mathrm{ml}^{-1}\right) ; \square \mathbf{\square}$, colistin $\left(5 \mu \mathrm{g} \mathrm{ml}^{-1}\right) ; \Delta \boldsymbol{\Delta}$, polymyxin (b) $\left(5 \mu \mathrm{g} \mathrm{ml}^{-1}\right)$. The data represent the averages of five or more independent experiments. Standard deviations for each experiment were not greater than $\pm 5 \%$ of the value shown. 
susceptibility to tetracycline can also be explained by the modification of surface transporters due to Sip production.

Some ABC transporters and efflux pumps support the secretion of soluble factors and materials needed for colonization and biofilm formation, and can function as either importers or exporters with diverse substrates (Fath and Kolter, 1993; Linton and Higgins, 1998; Mah and O'toole, 2001; Vallet et al., 2001). Moreover, there have been numerous reports of biofilm-associated resistance to antibiotics and its possible mechanisms in gram-negative bacteria (Costerton et al., 1999; Drenkard, 2003; Lai et al., 2009). In Pseudomonas and Salmonella, for example, the phenomenon seems to be similar to silica-induced resistance in Thermus cells, in that certain antibiotics such as $\beta$-lactams, aminoglycosides and fluoroquinolones are unaffected by biofilm-associated resistance (Mulcahy et al., 2008). In addition, other studies have shown that extracellular polymeric substances often have key functions in biomineralization (Karthikeyan and Beveridge, 2002; Omoike et al., 2004; Orange et al., 2009), and that the $\mathrm{S}$ layer is involved in biomineralization in the natural environment (Schultze-Lam et al., 1992). We are presently investigating these issues in Thermus cells by carrying out a metabolome analysis of cell aggregates in the presence of supersaturated silica.

\section{Analysis of the expression of the sip, multidrug} resistance $A B C$ transporter and efflux pump genes in the presence of supersaturated silica and antibiotics As described above and in earlier papers (Inagaki et al., 2003; Doi et al., 2009), T. thermophilus strains TMY and HB8 promote silica deposition, cell adhesion and resistance to peptide antibiotics in the presence of supersaturated silica, all of which may be related with Sip production. Sip, the multidrug resistant $\mathrm{ABC}$ transporter and/or the efflux pump system in Thermus may participate in interactions between the cell surface and silicic acid and between the cells and inorganic materials for cell adhesion. In addition, expression of these genes may contribute to the secretion of soluble factors and materials that support colonization or biofilm formation. To investigate these ideas, we analyzed expression of the sip, ABC transporter and efflux pump genes in strain HB8, with or without colistin and supersaturated silicic acid. Colistin was selected as the antibiotic for this experiment because the largest change in tolerance induced by supersaturated silicic acid was observed with colistin (Figure 3). Completion of the strain HB8 genome project (http://www.thermus.org/e_index.htm) enabled the design of specific primers for real-time PCR analysis of the genes in question. As shown in Table 1, sip gene, eight efflux pump genes and two multidrug resistance $\mathrm{ABC}$ transporter genes have been annotated in the HB8 genome.
We previously detected expression of sip using SDS-PAGE (Doi et al., 2009). We could also confirm the expression of sip by quantitative real-time PCR. Although remarkable transcription ( $>15$-folds) of sip gene was observed in cultures containing both colistin and supersaturated silica or containing only supersaturated silica, sufficient sip transcripts was detected in cells grown in TM broth containing only colistin (Figure 5). Gene expression of ABC transporters and efflux pumps was not inducible under any conditions (Figure 5). We therefore suggest their expression would not be stimulated by either supersaturated silica or a peptide antibiotic such a colistin. This suggests that the resistance to colistin conferred by supersaturated silica is not mediated by a drug export system involving transporters or pumps, but by increasing the robustness of the cell surface through embedding in silica. Consistent with that idea, the silica coating or silica embedded in the cell envelope apparently does not have efficacy against antibiotics that act in the cell cytoplasm such as ampicillin and so on.

Thermus species living in high-temperature zones in hot reservoirs attach to silica deposits or other materials to maintain their position within appropriate niches, which leads to the formation of biofilms. These bacteria can also survive exposure to highly siliceous solutions (>600 p.p.m), but under such conditions they are exposed to the menaces of antibacterial substances produced by other microorganisms. Bacitracin, colistin and polymyxin B are produced by Bacillus species, which grow in a variety of habitats. The resistance to antibiotics induced by supersaturated silica would be profitable for Thermus species living in natural geothermal water and soil environments; as Konhauser et al. (2008) suggested, Thermus species can use the mineral 'suit-of-armor' to their advantage.

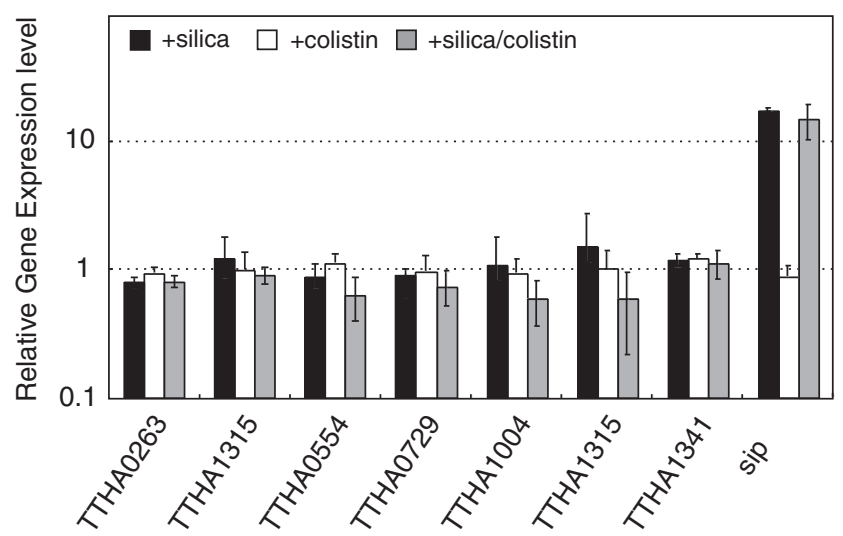

Figure 5 Relative gene expression levels (fold change, mean \pm s.d.) encoding putative efflux pumps, multidrug resistance ABC transporters and sip. Quantitation of these genes was determined relative to gyrB as a housekeeping gene by quantitative real-time PCR. Changes in gene expression in cells exposed to silica, colistin and silica/colistin are shown relative to that in cells grown in TM broth. Results shown are the mean of three independent RNA isolations. 
Although the molecular mechanisms by which Sip relates to silicification and drug resistance remain unclear, it might help Thermus don its 'armor.' As Sip is annotated as a solute-binding component of the $\mathrm{Fe}^{3+}$-binding $\mathrm{ABC}$ transporter, it remains uncertain whether this protein is located on the cell surface and whether it interacts directly with silica. We have succeeded in cloning sip and expressing it in Escherichia coli and are now investigating its abilities. The information obtained should provide clues to the significance and utilization of silica for the maintenance of the position and survival of Thermus species within limited natural niches. Moreover, it may shed light on how to control the formation of silica scale in geothermal power plants.

\section{Acknowledgements}

We are grateful to Dr Fumio Inagaki (Kochi Institute for Core Sample Research, JAMSTEC, Japan) for helpful advice. This research was supported in part by Kumamoto Technology and Industry Foundation (2005, 2006), by Kyushu University Interdisciplinary Programs in Education and Projects in Research Development (2008, 2009) and by JSPS KAKENHI No. 21580097.

\section{References}

Cook TL, Stakes DS. (1995). Biogeological mineralization in deep-sea hydrothermal deposits. Science 267: 1975-1979.

Costerton JW, Stewart PS, Greenberg EP. (1999). Bacterial biofilms: a common cause of persistent infections. Science 284: 1318-1322.

Doi K, Fujino Y, Inagaki F, Kawatsu R, Tahara M, Ohshima $\mathrm{T}$ et al. (2009). Stimulation of expression of a silicainduced protein (Sip) in Thermus thermophilus by supersaturated silicic acid. Appl Environ Microbiol 75: 2406-2413.

Drenkard E. (2003). Antimicrobial resistance of Pseudomonas aeruginosa biofilms. Microbes Infect 5: 1213-1219.

Fath MJ, Kolter R. (1993). ABC transporters: bacterial exporters. Microbiol Rev 57: 995-1017.

Fujino Y, Kawatsu R, Inagaki F, Umeda A, Yokoyama T, Okaue $\mathrm{Y}$ et al. (2008). Thermus thermophilus TMY isolated from silica scale taken from a geothermal power plant. J Appl Microbiol 104: 70-78.

Gooderham WJ, Bains M, Mcphee JB, Wiegand I, Hancock RE. (2008). Induction by cationic antimicrobial peptides and involvement in intrinsic polymyxin and antimicrobial peptide resistance, biofilm formation, and swarming motility of PsrA in Pseudomonas aeruginosa. J Bacteriol 190: 5624-5634.

Groisman EA, Kayser J, Soncini FC. (1997). Regulation of polymyxin resistance and adaptation to low- $\mathrm{Mg}^{2+}$ environments. J Bacteriol 179: 7040-7045.

Gunn JS, Lim KB, Krueger J, Kim K, Guo L, Hackett M et al. (1998). PmrA-PmrB-regulated genes necessary for 4-aminoarabinose lipid A modification and polymyxin resistance. Mol Microbiol 27: 1171-1182.
Handley KM, Turner SJ, Campbell KA, Mountain BW. (2008). Silicifying biofilm exopolymers on a hotspring microstromatolite: templating nanometer-thick laminae. Astrobiology 8: 747-770.

Higgins CF. (1995). The ABC of channel regulation. Cell 82: 693-696.

Inagaki F, Hayashi S, Doi K, Motomura Y, Izawa E, Ogata S. (1997). Microbial participation in the formation of siliceous deposits from geothermal water and analysis of the extremely thermophilic bacterial community. FEMS Microbiol Ecol 24: 41-48.

Inagaki F, Motomura Y, Doi K, Taguchi S, Izawa E, Lowe Dr et al. (2001). Silicified microbial community at steep Cone Hot Spring, Yellowstone National Park. Microbes Environ 16: 125-130.

Inagaki F, Motomura Y, Ogata S. (2003). Microbial silica deposition in geothermal hot waters. Appl Microbiol Biotechnol 60: 605-611.

Inagaki F, Yokoyama T, Doi K, Izawa E, Ogata S. (1998). Bio-deposition of amorphous silica by an extremely thermophilic bacterium, Thermus spp. Biosci Biotechnol Biochem 62: 1271-1272.

Karthikeyan S, Beveridge TJ. (2002). Pseudomonas aeruginosa biofilms react with and precipitate toxic soluble gold. Environ Microbiol 4: 667-675.

Konhauser KO, Lalonde SV, Phoenix VR. (2008). Bacterial biomineralization: where to from here? Geobiology 6 : 298-302.

Lai S, Tremblay J, Deziel E. (2009). Swarming motility: a multicellular behaviour conferring antimicrobial resistance. Environ Microbiol 11: 126-136.

Lalonde SV, Konhauser KO, Reysenbach AL, Ferris FG. (2005). The experimental silicification of Aquificales and their role in hot spring sinter formation. Geobiology 3: 41-52.

Lee H, Hsu FF, Turk J, Groisman EA. (2004). The PmrAregulated pmrC gene mediates phosphoethanolamine modification of lipid A and polymyxin resistance in Salmonella enterica. J Bacteriol 186: 4124-4133.

Linton KJ, Higgins CF. (1998). The Escherichia coli ATP-binding cassette (ABC) proteins. Mol Microbiol 28: 5-13.

Mah T-FC, O’toole GA. (2001). Mechanisms of biofilm resistance to antimicrobial agents. Trends Microbiol 9: 34-39.

Mcphee JB, Lewenza S, Hancock RE. (2003). Cationic antimicrobial peptides activate a two-component regulatory system, PmrA-PmrB, that regulates resistance to polymyxin $B$ and cationic antimicrobial peptides in Pseudomonas aeruginosa. Mol Microbiol 50: 205-217.

Mulcahy H, Charron-Mazenod L, Lewenza S. (2008). Extracellular DNA chelates cations and induces antibiotic resistance in Pseudomonas aeruginosa biofilms. PLoS Pathogens 4: e1000213.

Nishino K, Hsu FF, Turk J, Cromie MJ, Wosten MM, Groisman EA. (2006). Identification of the lipopolysaccharide modifications controlled by the Salmonella PmrA/PmrB system mediating resistance to Fe(III) and Al(III). Mol Microbiol 61: 645-654.

Omoike A, Chorover J, Kwon KD, Kubicki JD. (2004). Adhesion of bacterial exopolymers to alpha-FeOOH: inner-sphere complexation of phosphodiester groups. Langmuir 20: 11108-11114.

Orange F, Westall F, Disnar JR, Prieur D, Bienvenu N, Le Romancer M et al. (2009). Experimental silicification of the extremophilic Archaea Pyrococcus abyssi 
and Methanocaldococcus jannaschii: applications in the search for evidence of life in early earth and extraterrestrial rocks. Geobiology 7: 1-16.

Phoenix VR, Konhauser KO, Ferris FG. (2003). Experimental study of iron and silica immobilization by bacteria in mixed $\mathrm{Fe}-\mathrm{Si}$ systems: implications for microbial silicification in hot springs. Can J Earth Sci 40: 1669-1678.

Phoenix VR, Konhauser KO. (2008). Benefits of bacterial biomineralization. Geobiology 6: 303-308.

Roes S, Seydel U, Gutsmann T. (2005). Probing the properties of lipopolysaccharide monolayers and their interaction with the antimicrobial peptide polymyxin B by atomic force microscopy. Langmuir 21: 6970-6978.

Schultze-Lam S, Harauz G, Beveridge TJ. (1992). Participation of a cyanobacterial $S$ layer in fine-grain mineral formation. J Bacteriol 174: 7971-7981.

Stone KJ, Strominger JL. (1971). Mechanism of action of bacitracin: complexation with metal ion and $\mathrm{C}_{55}$-isoprenyl pyrophosphate. Proc Natl Acad Sci US A 68: 3223-3227.

Sun S, Negrea A, Rhen M, Andersson DI. (2009). Genetic analysis of colistin resistance in Salmonella enterica serovar Typhimurium. Antimicrob Agents Chemother 53: 2298-2305.

Toporski JK, Steele A, Westall F, Thomas-Keprta KL, Mckay DS. (2002). The simulated silicification of bacteria-new clues to the modes and timing of bacterial preservation and implications for the search for extraterrestrial microfossils. Astrobiology 2: 1-26.

Vallet I, Olson JW, Lory S, Lazdunski A, Filloux A. (2001). The chaperone/usher pathways of Pseudomonas aeruginosa: identification of fimbrial gene clusters (cup) and their involvement in biofilm formation. Proc Natl Acad Sci U S A 98: 6911-6916.

Wösten MM, Kox LF, Chamnongpol S, Soncini FC, Groisman EA. (2000). A signal transduction system that responds to extracellular iron. Cell 103: 113-125.

Yee N, Phoenix VR, Konhauser KO, Benning LG, Ferris FG. (2003). The effect of cyanobacteria on silica precipitation at neutral $\mathrm{pH}$ : implications for bacterial silicification in geothermal hot springs. Chem Geol 199: 83-90.

Zhou Z, Ribeiro AA, Lin S, Cotter RJ, Miller SI, Raetz CR. (2001). Lipid A modifications in polymyxin-resistant Salmonella typhimurium: PMRA-dependent 4-amino4-deoxy-L-arabinose, and phosphoethanolamine incorporation. J Biol Chem 276: 43111-43121. 